\title{
Avaliação Dos Projetos Sociais E Culturais: Uma Análise Da Relevância Dos Indicadores De Responsabilidade Social Nas Instituições
}

\section{Evaluation Of Social And Cultural Projects: An Analysis Of The Indicators Of Relevance Social Responsibility In Institutions}

\author{
Fernando de Almeida Santos
}

\begin{abstract}
Pós-doutorarando - USP-ECA, Doutor em Ciências Sociais - PUC-SP, Mestre em Administração - Universidade Presbiteriana Mackenzie, Especialista em Educação a distância, em Adminstraç̃o Financeira e em Avaliação Institucional, Graduado em Adminstração Pùblica e em Ciências Contábeis - Universidade Católica Dom Bosco, Graduado em Administração - UNIFIEO, Professor e Coordenador do Curso de Ciências Contábeis da PUC-SP - Ipiranga, Professor e pesquisador das Faculdades Metropolitandas Unidas, Professor De Contabailidade e Finanças nas Faculdades Integradas Rio Branco, Pesquisador das Faculdades Integradas ENIAC, Editor da Revista Científica Hermes. fernando@fernandoasantos.com.br
\end{abstract}

\section{Resumo}

Após a eclosão da crise de 2008 e a desaceleração econômica nas economias centrais, o Brasil pode perceber os efeitos das iniciativas sociais e culturais no que tange inclusão social e melhoria do bem-estar da população. A avaliação dessas políticas públicas, passa pela averiguação qualitativa e quantitativa dos projetos sociais e culturais. O referido estudo tem o objetivo de demonstrar, dentre as várias iniciativas de avaliação de projetos culturais, que a análise social se torna relevante. Tal análise permite a obtenção de uma abordagem relativa à responsabilidade social. Também, é destacada no artigo a importância do uso de indicadores e metas temporais e relativizadas. Para desenvolvimento do tema, inicialmente, descreve-se as principais formas de avaliação. Posteriormente, é apresentada a NBC T 15 (Normas Brasileiras de Contabilidade Técnica) que contempla as Informações de Natureza Social e Ambiental e que podem ser exigidas para as instituições prestarem contas da sua colaboração com projetos culturais. A NBC T 15 contempla quatro dimensões, que são: 1) a geração e a distribuição de riqueza; 2) os recursos humanos; 3) a interação da entidade com o ambiente externo; 4) a interação com o meio ambiente. Os resultados mostram que, por meio de uma visão sistêmica, as empresas que desenvolvem e/ou implementam projetos, não apenas podem elaborar este demonstrativo, como podem aprimorar e realizar análises horizontais, considerando a temporalidade e os a relativização dos indicadores.

Palabras chave: Avaliação; Cultura; Projetos Sociais; Projetos Culturais; Responsabilidade Social. 


\begin{abstract}
After the outbreak of the 2008 crisis and the economic slowdown in developed economies, Brazil may notice the effects of social and cultural initiatives regarding social inclusion and improving the well-being of the population. The assessment of these public policies, passes through qualitative and quantitative investigation of the social and cultural projects. This study aims to demonstrate, among several initiatives evaluation of cultural projects, the analysis of the social becomes relevant. This analysis allows us to obtain an approach to social responsibility. Also bighlighted in the article is the importance of the use of indicators and targets temporal and relativized. To develop the subject, initially describes the main forms of assessment. Subsequently, we present the NBC T 15 (Brazilian Accounting Standards Technical) which includes the Information Social and Environmental and which may be required for accountable institutions of its collaboration with cultural projects. NBC T 15 includes four dimensions which are: 1) the generation and distribution of wealth, 2) buman resources, 3) the interaction of the body with the external environment, 4) interaction with the environment. The results show that, through a systemic view, companies that develop and / or implement projects, not only can prepare this statement, and realize how they can enhance horizontal analyzes, considering the temporality and the relativization of the indicators.
\end{abstract}

Keywords: Evaluation, Culture, Social Projects, Cultural Projects; Social Responsibility.

\section{Introdução}

O Brasil é um país de dimensões continentais. Ao longo da década de 80, enfrentou uma das mais profundas e complexas crises econômicas. Os índices inflacionários alcançaram cifras inimagináveis. As taxas de crescimento econômico eram medíocres. O endividamento interno e externo desequilibravam as contas públicas. A estagnação econômica desse período ficou conhecida como a "década perdida."

Nos anos 90, durante o Governo de Fernando Henrique Cardoso, a implantação de mais um plano econômico de controle inflacionário - o Plano Real - colocou o país em uma trajetória de crescimento econômico sustentado e inflação controlada.
É sabido que a inflação se alimenta do desequilíbrio das contas públicas. O Plano Real assentou-se na premissa básica do controle e ajuste do orçamento público. Tais controles partiram de cortes de gastos públicos, privatização de empresas nacionais, reforma do estado e reforma monetária (Pires, 2010). O descontrole inflacionário penaliza as classes de menor poder aquisitivo que não possuem mecanismos de proteção contra a inflação. A corrosão do poder aquisitivo conduz essa parcela da sociedade a uma situação econômica crítica e de empobrecimento.

A estabilidade econômica e o controle inflacionário trouxeram uma nova condição econômica para a população brasileira, além da necessidade de uma revisão dos critérios e indicadores de desempenho utilizados para a realização de avaliação de programas sociais.

Segundo Costa e Castanhar (2003, p.973), “ [...] existem, entretanto, evidências de 
que esse desinteresse histórico está diminuindo rapidamente. As razões dessa mudança decorrem das profundas transformações observadas na sociedade e no Estado brasileiro desde meados dos anos 1980 e, particularmente, em anos mais recentes. Com efeito, nos anos 1980, a crise da dívida externa e a interrupção de um longo ciclo de crescimento econômico aprofundaram as desigualdades sociais presentes na realidade do país."

Ao longo dos anos 90, o Brasil realizou uma série de mudanças estruturais - a abertura comercial, a reforma do Estado, a desestatização - que agravavam a situação de desemprego e de geração de renda. $\mathrm{O}$ aumento da demanda por serviços sociais era inevitável.

A fim de se obter maior eficiência e maior impacto nos investimentos governamentais em programas sociais é imprescindível uma avaliação sistemática, contínua e eficaz de tais programas. O controle dos recursos públicos e a observância de seus efeitos são essenciais para o alcance de melhores resultados e reformulação de políticas sociais além de fornecer aos formuladores de políticas sociais e aos gestores de programas dados importantes para o desenho de políticas mais consistentes e para a gestão pública mais eficaz. (Costa e Castanhar, 2003)

É importante a realização de uma avaliação de desempenho adequada que norteie tais programas em que a busca por eficiência e eficácia sejam uma constante. A busca dessa melhoria passa pela avaliação do desempenho dos programas públicos, o que enseja a possibilidade de avaliar a própria performance do aparelho estatal. Ou seja, quando se estabelecem a eficiência, eficácia e efetividade como medidas de sucesso da ação governamental, impõe- se criar também meios de avaliar diferentes alternativas para se obter resultados equivalentes (Kettl, 1996:84)

O objetivo deste trabalho consiste em demonstrar que, atualmente, muitas iniciativas para avaliar projetos culturais, geralmente, não contemplam aspectos institucionais em relação à responsabilidade social e sustentabilidade. Portanto, neste trabalho propõe-se a incluir indicadores institucionais de responsabilidade social das instituições que implementam projetos sociais e culturais.

O referido artigo se propõe, ainda, a mostrar a relevância em inserir a mensuração dos resultados oriundos das ações de responsabilidade social, inclusive, incluindo análise contábil e financeira.

O estudo tem como hipótese a importância de uma visão sistêmica que contemple as Instituições que estão elaborando e/ou implantando projetos sociais e culturais. Para tal, apresenta a proposta de implantação de indicadores de natureza social e ambiental e da necessidade de análises temporais, para identificar a evolução e o desenvolvimento de quocientes que possibilitem comparar e relativizar indicadores. No trabalho, ainda, se aborda a relevância de acompanhamento em diferentes períodos, por meio da análise de valores presentes líquidos e taxa interna de retorno, se o projeto visar a rentabilidade. 
$\mathrm{O}$ artigo divide-se em três seções. A primeira seção discorrerá sobre complexidade metodológica de avaliação dos projetos sociais. A mensuração dos resultados obtidos com a consecução dos projetos sociais exige, ao mesmo tempo, uma visão sistêmica dos resultados bem como a seleção de indicadores que expressem a eficácia das ações adotadas nestes projetos.

A segunda seção abordará a NBC T 15, (Normas Brasileiras de Contabilidade Técnica) que contempla as Informações de Natureza Social e Ambiental. Um demonstrativo contábil brasileiro que tem origem no Balanço Social. Este demonstrativo, embora seja um avanço para a gestão das empresas, não é obrigatório e necessita de indicadores que possibilitem a análise horizontal e de quocientes. Tais indicadores são muito contributivos para percepção da contribuição social das empresas. A NBC T 15 contempla 4 dimensões, que são: 1) a geração e a distribuição de riqueza; 2) os recursos humanos; 3) a interação da entidade com o ambiente externo; 4) a interação com o meio ambiente. Ao final, serão relatadas as considerações finais.

\section{A Avaliação De Projetos Sociais} Em Foco

Segundo Aguilar e Ander-Egg (1994), o termo avaliação consiste em atribuir valor a algo. A avaliação representa uma atividade bastante antiga, que data dos primórdios da história da humanidade (Contandriopoulos et al.,1997).

A avaliação dos programas públicos data dos idos da Segunda Guerra Mundial, decorrente da necessidade de melhoria da eficácia da aplicação dos recursos pelo Estado. Segundo Aguilar e Ander-Egg, (1994), quando se trata de conferir valor a programas ou serviços é imprescindível situar a avaliação no campo das modalidades de intervenção social e, consequentemente, das ciências sociais. Recorrese à utilização de "procedimentos que, apoiados no uso do método científico, servem para identificar, obter e proporcionar a informação pertinente e julgar o mérito e o valor de algo de maneira justificável" - a chamada avaliação em sentido estrito ou avaliação sistemática (Aguilar \& Ander-Egg, 1994:23).

Segundo Aguilar e Ander-Egg (1994) observa-se uma diferenciação metodológica entre as duas avaliações. A avaliação sistemática pressupõe a utilização de um método, diferente da avaliação de fatos cotidianos em que baseados em determinados critérios de valor são emitidos julgamentos. Em verdade, realizase uma avaliação que emite um julgamento com diligência, ou seja, com propósitos.

Segundo Contandriopoulos et al. (1997:31), "Este julgamento pode ser resultado da aplicaşão de critérios e de normas (avaliação normativa) on se elaborar a partir de um procedimento cientifico (pesquisa avaliativa)".

A avaliação normativa, como o próprio nome diz, emite julgamento comparando com 
uma norma ou métrica. "A comparaşão do uso dos recursos empregados e sua organização(estrutura), os serviços ou os bens produzidos (processo), e os resultados obtidos, com critérios e normas" (Contandriopoulos et al., 1997:34). Ou seja, a avaliação normativa técnica, organizacional e das relações interpessoais) e dos resultados (Contandriopoulos et al., 1997)

A pesquisa avaliativa consiste em realizar o julgamento ex-post de uma intervenção utilizando métodos científicos. Avalia-se os fundamentos teóricos, os efeitos e o rendimento de uma intervenção. Tais métodos científicos utilizados podem ser questionados quanto à sua eficácia e eficiência em captar os efeitos e rendimentos de tais intervenções. (Contandriopoulos et al., 1997)

Sustentamos que a análise de programas ou de seus constituintes, à luz de critérios e normas, sejam estes cientificamente estabelecidos ou não, requer para sua execução, determinado rigor metodológico.

Em suma, não existe uma única via de acesso metodológica atrás da avaliação de programas sociais, uma vez que não existe uma verdade única na esfera dos fenômenos sociais. Como mostra Pinto (1986, apud Acúrcio et al., 1991:51) “[...] Dependendo do postulado teórico assumido, encaminhar-se-á em uma ou outra direção e se selecionarão algumas dimensões para análise, em detrimento de outras. [...] O que torna científica uma avaliação não é a descoberta de uma única verdade, e sim, o esforço para analisa a estrutura, do processo (nas dimensões

verificar observações e validar o seu significado ou seus diferentes significados".

É preciso delimitar com clareza o objeto da avaliação, ou melhor, o que se pretende avaliar. Atualmente, na área social, existem modelos centrados em objetivos. Estes são utilizados como requisitos para definições dos padrões comportamentais, seleção e criação de situações de teste que evocam esses padrões e em termos de compreensão para que os resultados sejam utilizados de forma construtiva. Ou seja, hoje, podem ser utilizados com a finalidade de corrigir discrepâncias entre os objetivos almejados e os alcançados em determinada etapa do projeto. Porém, esse tipo de avaliação engendra algumas restrições. Quando o alcance do trabalho realizado ultrapassa os limites dos seus objetivos, por exemplo, outros resultados podem surgir e mudanças no próprio projeto podem acarretar alterações nos resultados.(Assumpção e Campos, 2011). A utilização dessa abordagem de avaliação, quando utilizada de forma isolada, não permite olhar para essas outras possibilidades, em função de suas restrições para alterar metas e objetivos, perdendo,com isso, a oportunidade de explorar outros aspectos relevantes da realidade social. Por outro lado, avaliações centradas na administração, ou seja, focadas nas decisões de seus agentes, tornam-se um "processo de coleta de informações úteis à tomada de decisão e, sendo assim, o objetivo do processo é aumentar o grau de acerto nas decisões tomadas". (Assumpção e Campos, 2011). 
Quadro 1 - Principais características das avaliações centradas na administração.

\begin{tabular}{|l|l|}
\hline Conceito & $\begin{array}{l}\text { Coleta de informações } \\
\text { úteis à tomada de } \\
\text { decisões. }\end{array}$ \\
\hline Usos & $\begin{array}{l}\text { Subsidiar informações } \\
\text { úteis e ajudar os gestores } \\
\text { dos projetos na tomada de } \\
\text { decisão. }\end{array}$ \\
\hline $\begin{array}{l}\text { Principais } \\
\text { autores }\end{array}$ & $\begin{array}{l}\text { Stufflebeam, Alkim e } \\
\text { Provus }\end{array}$ \\
\hline Vantagens & $\begin{array}{l}\text { Abrangência, abordagem } \\
\text { sistêmica e sensibilidade } \\
\text { às necessidades }\end{array}$ \\
\hline Desvantagens & $\begin{array}{l}\text { Ênfase na eficiência, } \\
\text { premissas de ordem } \\
\text { previsibilidade. Foco } \\
\text { centrado na visão } \\
\text { dos líderes. }\end{array}$ \\
\hline
\end{tabular}

Fonte: Assumpção e Campos (2011)

A avaliação centrada em especialistas, por sua vez, depende dos especialistas e da qualificação profissional dos avaliadores para julgar a qualidade de qualquer atividade que esteja sendo avaliada. Vários são os processos específicos de avaliação, tais como: exames de doutoramento, pareceres específicos, painéis para revisão de projetos, entre outros. Tais modelos geram pareceres baseados em juízos emanados dos conhecimentos e experiências profissionais buscando padrões consensuais. $\mathrm{O}$ quadro 2 apresenta as principais características dos modelos centrados em especialistas.
Quadro 2 - Principais características das avaliações centradas em especialistas.

\begin{tabular}{|c|c|}
\hline Conceito & $\begin{array}{lr}\text { Especialistas } & \text { por meio de } \\
\text { seus } & \text { conhecimentos } \\
\text { específicos } & \text { fornecem } \\
\text { informações } & \text { necessárias } \\
\text { para julgamento dos } \\
\text { projetos. }\end{array}$ \\
\hline Usos & $\begin{array}{l}\text { Julgamentos profissionais de } \\
\text { qualidade em projetos sociais. }\end{array}$ \\
\hline $\begin{array}{l}\text { Principais } \\
\text { autores }\end{array}$ & Eisner e grupos de acreditação \\
\hline Vantagens & $\begin{array}{l}\text { Cobertura ampla, eficiência e } \\
\text { capitaliza o juízo humano. }\end{array}$ \\
\hline Desvantagens & $\begin{array}{l}\text { Visão superficial do contexto, } \\
\text { uso exagerado da intuição. } \\
\text { Confiança nas qualificações } \\
\text { dos especialistas. }\end{array}$ \\
\hline
\end{tabular}

Fonte: Assumpção e Campos (2011)

Em suma, o processo de avaliação será facilitado e mais útil se baseado em um planejamento consistente que estabeleça as relações causais existentes entre: atividades $\Leftrightarrow$ produtos; produtos $\Leftrightarrow$ resultados; resultados $\Leftrightarrow$ objetivos específicos. Ou seja, efeitos que produzam o impacto pretendido pela missão do programa, de tal sorte que se busque fazer com que as atividades de fato contribuam para o alcance desse mesmo propósito.

Daí a importância em analisar a eficácia da utilização da Contabilidade e os seus Instrumentos de Informações de Natureza Social e Ambiental, conforme descritos a seguir. 
2. A Visão Sistêmica $\mathrm{Da}$ Nbc $\mathrm{T} 15$ (Normas Brasileiras De Contabilidade Técnica) Informações De Natureza Social E Ambiental

Os projetos sociais e culturais, muitas das vezes, não são resultantes de pessoa física, pois possuem uma pessoa jurídica que $\mathrm{O}$ representa. Esta pessoa jurídica pode ser um órgão governamental, uma organização não governamental, uma fundação ou uma entidade privada.

As formas de análise destes projetos sociais e culturais, por sua vez, costumeiramente abordam a proposta de desenvolvimento dos projetos ou as suas etapas de realização. Geralmente, há, como indicadores para análise das empresas proponentes, aspectos gerais institucionais, como o número de anos de existência da empresa, o seu patrimônio líquido ou a sua tradição em projetos sociais. Observase, porém, que o fato das empresas possuírem toda esta tradição não significa que possuem responsabilidade social ou que trazem contribuição significativa para aspectos sociais, econômicos ou ambientais.

\subsection{A Visão Sistêmica Das Empresas Que Apresentam Projetos Sociais}

É importante destacar a necessidade da visão sistêmica para análise dos projetos sociais e não limitar a uma análise simplista do projeto, até pelo fato de que é muito relevante identificar qual a contribuição histórica das instituições que desenvolvem projetos sociais.

Conforme Bertalanffy (901-1972; in Nogueira, 2007), a teoria geral dos sistemas, em especial dos chamados sistemas abertos, influenciou várias disciplinas, entre elas a teoria das organizações. O autor afirma, ainda, que segundo esse enfoque todos objetos complexos e corpos organizados podem ser considerados sistemas: uma máquina, um organismo, uma floresta etc.

Nogueira (2007) afirma que sistema é um conjunto de partes que forma um todo organizado. Portanto, com esta perspectiva, é importante conceber que os projetos sociais e culturais fazem parte de um sistema que é composto pela instituição que elabora e executa o projeto, além da sua intervenção social interna ou externa à sociedade.

Dentro desta perspectiva, se faz necessário um sistema de informações, para acompanhamento e controle gerencial das ações das instituições, relativas a aspectos sociais, econômicos e ambientais. Há, portanto, necessidade de identificar quais informações são relevantes para tais instituições demonstrarem a sua importância e contribuições sociais, pois um projeto social não se justifica se o conjunto de ações da instituição não tem um impacto social positivo.

Para Laudon e Laudon (2001) "sistema de informação pode ser definido tecnicamente como um conjunto de componentes interrelacionados que coleta (ou recupera), processa, armazena e distribui informações para 
dar suporte à tomada de decisão ou controle da organização.” Complementando esta visão, Anthony e Govidarajan (2006) afirmam que: "Um sistema é um procedimento preestabelecido para executar uma atividade ou um conjunto de atividades; geralmente, as atividades são repetitivas." Observa-se que os dados necessários para as instituições são, na maioria das vezes, informações possíveis de padronização, o que facilita o desenvolvimento de instrumentos institucionais, mas é necessária uma visão sistêmica e gerencial.

Para Anthony e Govidarajan (2006), o controle gerencial é o processo pelo qual os executivos influenciam outros membros da organização, para que obedeçam as estratégias adotadas.

Conforme é apresentado na figura 1, para o desenvolvimento do paradigma sistêmico, deve-se considerar os seguintes aspectos:

Ambiente: Que consiste os aspectos internos e externos nos quais o objeto analisado está inserido. No caso dos projetos sociais e culturais, consiste em aspectos como: pessoas envolvidas, pessoas beneficiadas, posturas institucionais, conjuntura política, conjuntura econômica e o contexto. Também devem ser considerados aspectos institucionais como: desenvolvimento ou desempenho e porte institucional.

Entrada: Composta pelos dados que serão fornecidos para o sistema a fim de possibilitar acompanhamento, controle o e tomada de decisões.

Saída: A saída comporta os produtos e serviços resultantes do sistema, inclusive as análises gerenciais e a capacidade de transformar os dados em informações que contribuam para o desenvolvimento dos projetos.

Avaliação ou Feedback: que, conforme Nogueira (2007), consiste no processo racional de verificação dos resultados e de retorno, como corrigir e dar continuidade ao processo indefinidamente.

A avaliação deve funcionar como uma retroalimentação do sistema, pois contribui para evolução contínua, para análise do que de fato foi contributivo para o desenvolvimento das políticas sociais e para o desenvolvimento dos projetos. 


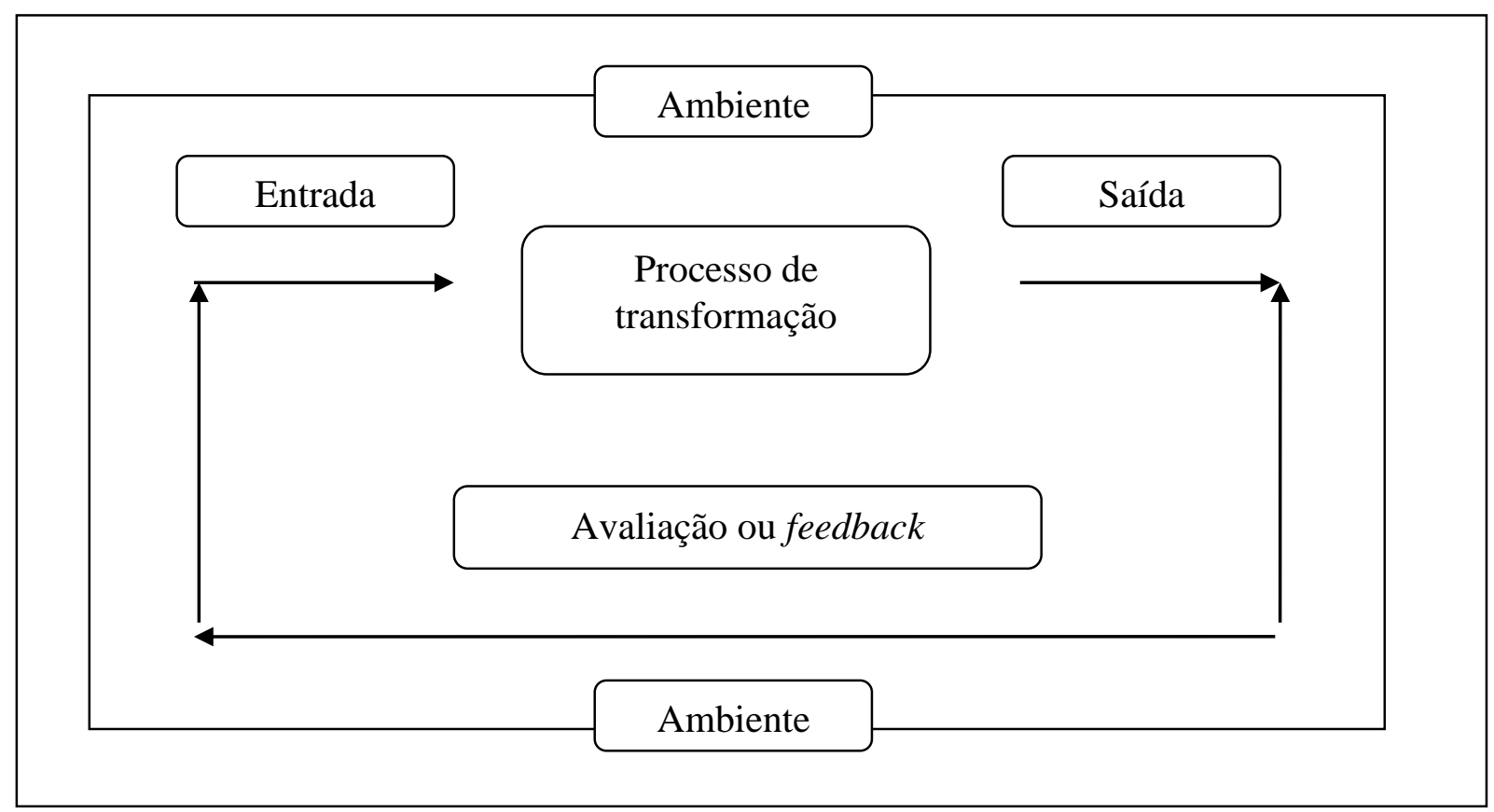

Figura 1 - Elementos de um sistema aberto Fonte: NOGUEIRA, A. J. F. M. (2007).

Conforme descrito, por meio de uma abordagem sistêmica e gerencial das instituições, é possível desenvolver critérios e parametrizações de análise, mas é necessário identificar quais são os indicadores essenciais e desenvolver formas de análise válidas e compatíveis com as metas dos projetos sociais e culturais.

Para iniciar a discussão sobre os dados e informações institucionais relevantes das empresas que elaboram projetos sociais ou culturais, este trabalho considerou as seguintes premissas:

a) Tais informações não podem se limitar ao ambiente dos projetos. Pois uma empresa que possui projetos sociais ou culturais relevantes, mas que não contribui com a sustentabilidade, pode utilizar dos projetos sociais para marketing, mas não ser positiva para a sociedade. Logo, devem ser institucionais.

b) Os dados, ainda que institucionais, devem ter impactos internos e externos, pois não é possível considerar aspectos sociais, sem refletir sobre a sociedade. Deve-se considerar, portanto a relação dos dados com o desenvolvimento do ambiente.

c) É fundamental a análise temporal dos projetos e das instituições, para verificar o desempenho, pois desta forma é possível compreender o seu desenvolvimento.

d) Também, é fundamental relativizar os dados. É preciso 
compreender que é necessário relativizar em relação ao porte e às características institucionais. A contribuição de um projeto social deve considerar, portanto, a capacidade contributiva das instituições para a sociedade.

e) A capacidade financeira da instituição para dar continuidade ao projeto até o seu momento de conclusão.

Logo, conforme a visão sistêmica, não se pode limitar a análise financeira do projeto à sua viabilidade ou limitar os aspectos institucionais ao fato de que a empresa existe há muitos anos. Para o desenvolvimento de uma proposta sistêmica, a seguir, é apresentada a origem do Balanço Social e a NBC T 15.

\subsection{A Origem Do Balanço Social E A Nbc T} 15 - Informações De Natureza Social E

\section{Ambiental}

Uma forma de apresentar a responsabilidade social e ambiental é por meio do Balanço Social. O Balanço Social teve origem na Europa e consiste em um demonstrativo anual, que pode ser elaborado pelas instituições públicas ou privadas.

Em 1997 começou a ser utilizado no Brasil, porém nunca foi obrigatório, de forma que as instituições elaboram a fim de prestar contas para a sociedade das suas ações sociais.
Em 1998, o Ibase-Instituto Brasileiro de Análises Sociais e Econômicas lançou o Selo Balanço Social Ibase/Betinho, com o objetivo de estimular a participação das empresas na elaboração e divulgação do Balanço Social. Este fato estimulou o crescimento do número de empresas que passaram a desenvolver o balanço social.

Posteriormente, no Brasil, algumas empresas passaram a preferir realizar compras de empresas que elaboram o Balanço Social, para verificar se possuem projetos sociais e culturais e qual a forma de interação e colaboração com a comunidade, além de identificar o compromisso com o desenvolvimento sustentável.

Conforme Tinoco (2010), o Balanço Social tem por objetivo ser equitativo e comunicar informação que satisfaça a necessidade de quem dela precisa.

O Brasil, identificando este movimento, em 2004, por meio do Conselho Federal de Contabilidade, aprovou a Norma Brasileira de Contabilidade NBC T-15, que passou a vigorar em $1^{\circ}$ de janeiro de 2006. Esta norma estabelece procedimentos para evidenciação de informações de natureza social e ambiental, com o objetivo de demonstrar à sociedade a participação e a responsabilidade social da entidade e consiste na regulamentação do Balanço Social.

O objetivo na aprovação da NBC T-15 foi definir os indicadores mínimos para elaboração dos Balanços Sociais, possibilitando critérios mínimos para controle de qualidade 
destes demonstrativos. Portanto, as empresas que optarem por publicar o Balanço Social necessitam desta Norma.

A norma define por informações de natureza social e ambiental as seguintes dimensões:

a) a geração e a distribuição de riqueza;

b) os recursos humanos;

c) a interação da entidade com o ambiente externo;

d) a interação com o meio ambiente.

Observa-se que cada dimensão tem seus indicadores próprios e, a seguir, é apresentado o quadro 3, que consiste em um resumo das informações a serem divulgadas no Balanço Social, conforme a NBC T 15:

Quadro 3 - Informações a serem divulgadas no Balanço Social, conforme a NBC T-15

1 - Geração e Distribuição de Riqueza

Riqueza gerada e distribuída pela entidade, apresentada conforme a Demonstração do Valor Adicionado, definida na NBC T 3.

\section{2 - Recursos Humanos}

2.1 Quanto à remuneração e benefícios concedidos aos empregados, administradores, terceirizados e autônomos:

a) remuneração bruta segregada por empregados, administradores, terceirizados e autônomos;

b) relação entre a maior e a menor remuneração da entidade, considerando os empregados e os administradores;

c) gastos com encargos sociais;

d) gastos com alimentação;

e) gastos com transporte;

f) gastos com previdência privada;

g) gastos com saúde;

h) gastos com segurança e medicina do trabalho;

i) gastos com educação (excluídos os de educação ambiental);

j) gastos com cultura;

k) gastos com capacitação e desenvolvimento profissional;

1) gastos com creches ou auxílios-creche;

m) participações nos lucros ou resultados.

Estas informações devem ser expressas monetariamente pelo valor total do gasto com cada item e a quantidade de empregados, autônomos, terceirizados e administradores beneficiados. 


\subsection{Nas informações relativas à composição dos recursos humanos, devem ser evidenciados:}

a) total de empregados no final do exercício;

b) total de admissões;

c) total de demissões;

d) total de estagiários no final do exercício;

e) total de empregados portadores de necessidades especiais no final do exercício;

f) total de prestadores de serviços terceirizados no final do exercício;

g) total de empregados por sexo;

h) total de empregados por faixa etária, nos seguintes intervalos:

- menores de 18 anos

- de 18 a 35 anos

- 36 a 60 anos

- acima de 60 anos

i) total de empregados por nível de escolaridade, segregados por:

- analfabetos

- com ensino fundamental

- com ensino médio

- com ensino técnico

- com ensino superior

- pós-graduados

j) percentual de ocupantes de cargos de chefia, por sexo.

Quadro 3 - Informações a serem divulgadas no Balanço Social, conforme a NBC T-15 (cont.) 2.3 Nas informações relativas às ações trabalhistas movidas pelos empregados contra a entidade, devem ser evidenciados:

a) número de processos trabalhistas movidos contra a entidade;

b) número de processos trabalhistas julgados procedentes;

c) número de processos trabalhistas julgados improcedentes;

d) valor total de indenizações e multas pagas por determinação da justiça.

Para o fim desta informação, os processos providos parcialmente ou encerrados por acordo devem ser considerados procedentes.

3- Interação da Entidade com o Ambiente

Externo

3.1 Nas informações relativas à interação com a comunidade, devem ser evidenciados os totais dos investimentos em:

a) educação, exceto a de caráter ambiental;

b) cultura;

c) saúde e saneamento;

d) esporte e lazer, não considerados os patrocínios com finalidade publicitária;

e) alimentação. 


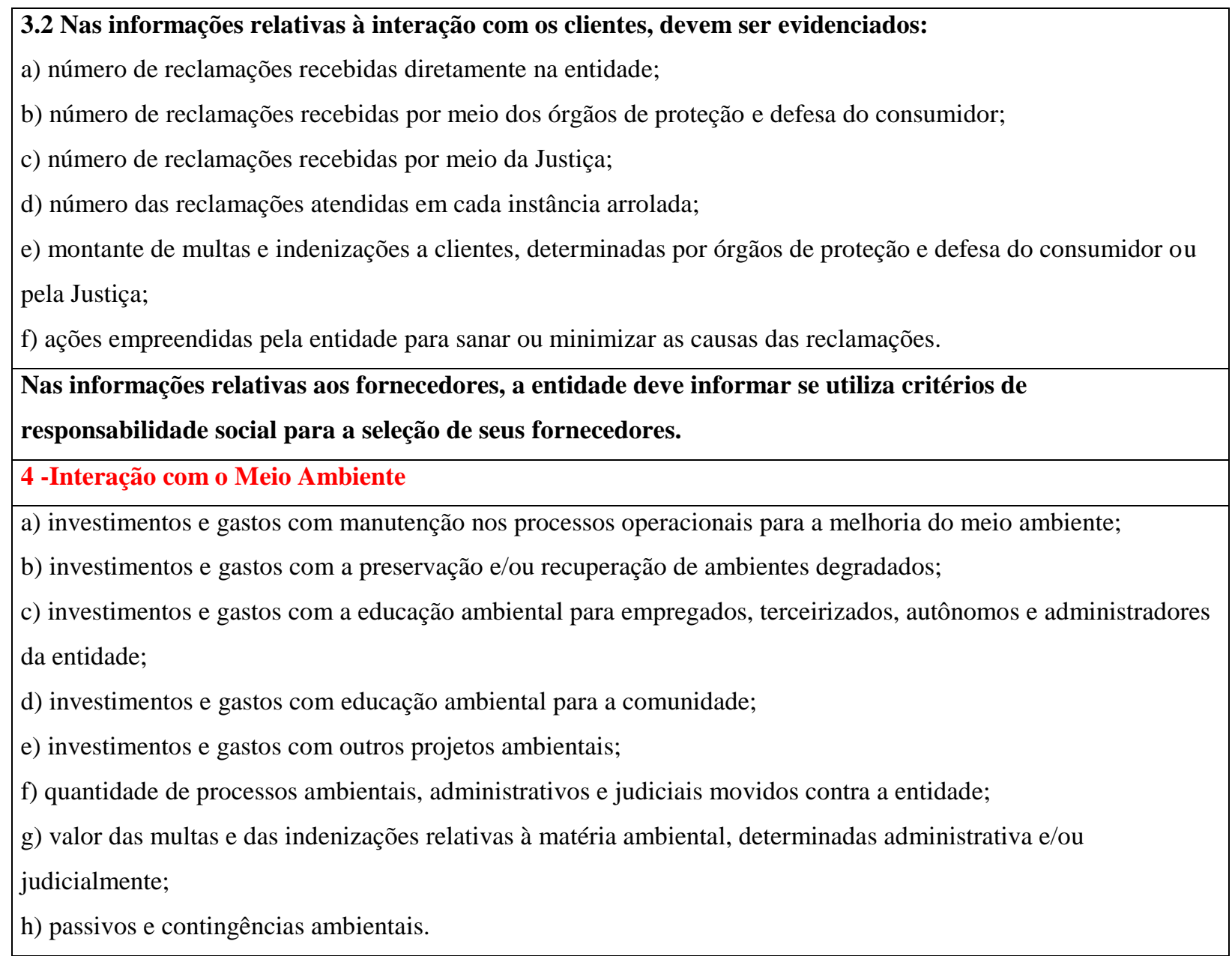

Fonte: SANTOS, F. A. (2009)

Observa-se que o Balanço Social, apesar de abordar os aspectos relevantes da instituição sobre as quatro dimensões citadas, deve ser aprimorado e, sem análise temporal e sem relativização pouco contribui para o desenvolvimento dos projetos sociais. Portanto, é necessário análise e contextualização dos balanços sociais.

\subsection{Possíveis Formas De Análise Dos Demonstrativos Sociais}

A seguir, serão apresentadas duas propostas de análise que são: a) análise horizontal, que possibilita análise temporal; b) análise por quocientes, que consiste na estruturação de quocientes que possibilitam comparar e relativizar os dados.

\subsubsection{Análise Horizontal}

A análise horizontal de indicadores possibilita uma visão quantitativa do desempenho anual do balanço Social. O ideal para análise é, sempre que possível, utilizar 5 anos para comparação, pois é uma forma que facilita esta compreensão da evolução e consiste em uma metodologia da análise horizontal, muito utilizada para acompanhamento e controle de demonstrações financeiras. Ao 
abordar tais demonstrações financeiras, Matarazzo (2010) afirma que a evolução de cada conta mostra os caminhos trilhados pela empresa e as possíveis tendências.

Assaf Neto (2010) destaca que a análise horizontal é desenvolvida por meio de números índices, que é a relação existente entre o valor de uma conta contábil ou grupo de contas em determinada data e seu valor obtido na database, permitindo sua comparação no tempo. É um valor relativo, um número adimensional que pode variar no tempo, na mesma proporção das grandezas originais, dependendo do objetivo que se quer atingir, como calcular a evolução no tempo e a variação de um ano a outro de uma determinada conta.

Ghisoni (2011) denomina a análise horizontal como análise dinâmica e afirma que este tipo de abordagem que confronta as datas e informações relativas a diferentes períodos representa um movimento de um período para o outro. O autor afirma, ainda, que é como se comparar fotografias que possibilitem compor um filme.

A análise horizontal consiste em comparar valores de uma mesma conta ou grupo de contas, em diferentes períodos. Esta metodologia, porém, pode ser utilizada, também, para dados quantitativos que não são financeiros.

Para exemplificar, foi feito um recorte do balanço social, com o item 2, que contempla as informações relativas à interação com a comunidade, para análise horizontal, conforme é apresentado na tabela 1:

Quadro 4: Exemplo com dados fictícios de análise horizontal das Informações relativas à interação com a comunidade.

\begin{tabular}{|c|c|c|c|c|c|c|c|c|c|c|}
\hline $\begin{array}{l}\text { 3.1 Informações relativas à interação com a } \\
\text { comunidade - Totais de Investimentos em Reais: }\end{array}$ & \multicolumn{2}{|c|}{2008} & \multicolumn{2}{|c|}{2009} & \multicolumn{2}{|c|}{2010} & \multicolumn{2}{|c|}{2011} & \multicolumn{2}{|c|}{2012} \\
\hline a) educação, exceto a de caráter ambiental; & 40.000 & $100 \%$ & 50.000 & $125 \%$ & 70.000 & $175 \%$ & 60.000 & $150 \%$ & 80.000 & $200 \%$ \\
\hline b)cultura; & 60.000 & $100 \%$ & 40.000 & $67 \%$ & 80.000 & $133 \%$ & 85.000 & $142 \%$ & 90.000 & $150 \%$ \\
\hline c) saúde e saneamento; & 20.000 & $100 \%$ & 30.000 & $150 \%$ & 40.000 & $200 \%$ & 27.000 & $135 \%$ & 25.000 & $125 \%$ \\
\hline $\begin{array}{l}\text { d) esporte e lazer, não considerados os } \\
\text { patrocínios com finalidade publicitária; }\end{array}$ & 40.000 & $100 \%$ & 60.000 & $150 \%$ & 80.000 & $200 \%$ & 85.000 & $213 \%$ & 70.000 & $175 \%$ \\
\hline e) alimentação. & 80.000 & $100 \%$ & 100.000 & $125 \%$ & 60.000 & $75 \%$ & 70.000 & $88 \%$ & 80.000 & $100 \%$ \\
\hline Total & 240.000 & $100 \%$ & 280.000 & $117 \%$ & 330.000 & $138 \%$ & 327.000 & $136 \%$ & 345.000 & $144 \%$ \\
\hline
\end{tabular}

Elaborado pelos autores com dados fictícios.

Observa-se que neste exemplo foram utilizados 5 anos, o que possibilita uma análise de um período significativo, além de possibilitar visualizar tendência, conforme observado no gráfico 1: 
Gráfico 1: Exemplo de gráfico com dados temporais das Informações relativas à interação com a comunidade.

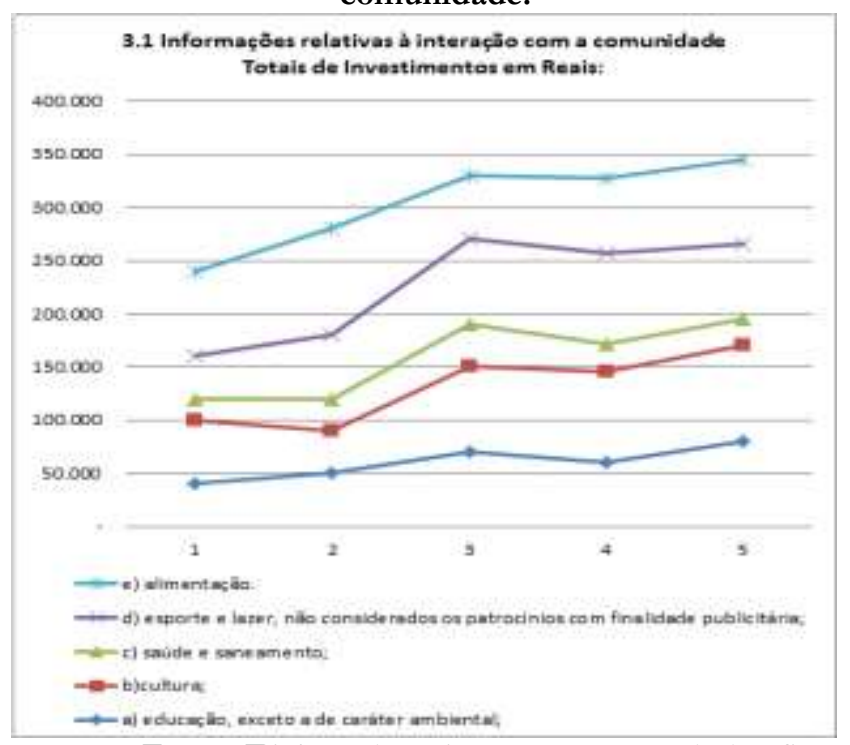

Fonte: Elaborado pelos autores com dados fictícios.

Conforme demonstra o gráfico 1, apesar de eventuais quedas, é perceptível o crescimento do investimento institucional no decorrer do anos. Esta análise horizontal é fundamental para esta percepção.

\subsubsection{Análise Por Meio De Quocientes}

A análise de quocientes consiste em comparar diferentes grandezas. O objetivo é verificar a relação entre diferentes aspectos. Esta técnica é plenamente aplicável para análise do Balanço Social de empresas, entre elas, as que possuem projetos sociais ou culturais.

Como exemplo é possível citar os dados apresentados no item 2.3.1, em que uma Instituição Ampliou 50\% o seu investimento em cultura, portanto passou de $\mathrm{R} \$ 60.000,00$ para $\mathrm{R} \$$ 90.000,00. Sem considerar aspectos inflacionários, pode-se afirmar que foi um crescimento muito significativo em um espaço curto de tempo, mas, novamente, dentro de uma visão sistêmica, não se pode limitar a análise apenas ao crescimento temporal, temos que relativizar este valor. Portanto, podemos comparar o que representa estes montantes em reais com diversos aspectos, como número de funcionários, faturamento e outros. O mesmo é possível com outros indicadores, pois pode-se comparar vários outros aspectos a fim de melhor descrever a responsabilidade social destas empresas, como o número de funcionárias mulheres, em comparação ao total de funcionários. Esta análise por quocientes, ainda, possibilita uma análise horizontal temporal, além de possibilitar relativizar os dados em relação ao porte institucional ou a determinadas características que possibilitam compreender melhor a responsabilidade social das empresas que investem em projetos.

A Universidade do Porto em 2011, ao apresentar e divulgar externamente o seu Balanço Social, destacou alguns quocientes 
muito relevantes que possibilitam esta análise, porém se limitou há alguns aspectos sociais e de formação acadêmica.

\subsubsection{Desenvolvimento De Indicadores}

O Balanço Social foi um avanço para o desenvolvimento de ações sociais, para a sustentabilidade e para a construção e implantação dos projetos sociais culturais. Porém, é necessário prosseguir este avanço, por meio do desenvolvimento e aprimoramento de indicadores, da obrigatoriedade do desenvolvimento de balanços sociais, da inclusão de indicadores que, de forma direta, acompanhem os investimentos das empresas em projetos sociais e culturais.

O desenvolvimento dos balanços sociais possibilita atender aspectos relativos à abordagem sistêmica citada e podem ser utilizados como mais um instrumento de avaliação dos projetos sociais, além de possibilitar análises temporais, comparar dados e relativizar as informações.

A visão sistêmica ocorre pelos seguintes motivos:

a) Não se limita a análise do projeto, pois possibilita um olhar institucional. Determinada instituição pode ter um projeto social ou cultural relevante, mas a empresa possui outras ações que, no conjunto, demonstram serem prejudiciais à sociedade. Logo, é importante um instrumento institucional que possibilite uma visão de quanto realmente é a colaboração da empresa pública ou privada em relação aos aspectos sociais e culturais.

b) O NBC T 15 não se restringe a aspectos pontuais, pois contempla 4 dimensões que são:

1) A geração e a distribuição de riqueza Dados capazes de possibilitar a visão de qual a contribuição da instituição com a sociedade e de que forma alocou os recursos. Determinada instituição teve um ingresso de determinada quantia em 2012. Este demonstrativo se propõe a demonstração de como esta quantia contribuiu e para quem contribuiu na sociedade.

2) A alocação dos recursos humanos: Nesta parte o demonstrativo mostra qual a forma que os recursos foram alocados para as pessoas. Como está a divisão e quais os agentes e o perfil destes agentes que recebem tais recursos.

3) A interação da entidade com o ambiente externo: Importante parte do instrumento, que apresenta a relação da instituição com a sociedade e a sua contribuição em aspectos sociais e 
culturais. Aborda aspectos educacionais, culturais, saúde e saneamento, esporte e lazer, alimentação e aspectos culturais.

4) $\mathrm{A}$ interação com o meio ambiente: $\mathrm{A}$ última parte do instrumento, consiste em apresentar em que as instituições se relacionam com o meio ambiente.

c) Com os dados, é possível criar novos indicadores, por meio de comparação de valores, ou seja, quocientes que possibilitem relativizar os dados, conforme o porte ou o perfil institucional.

d) Há a possibilidade, não apenas de realizar e publicar o balanço social, mas, da análise horizontal, ou seja, temporal, que permite analisar períodos diferentes para compreender o desempenho institucional de dados ou indicadores.

\section{Considerações Finais}

Nos anos 90, deu-se o início do mais amplo e ousado programa de Reforma do Estado capitaneado pela ampla participação da sociedade nas tomadas de decisões públicas. O contexto da globalização e o reordenamento institucional, nos quais as sociedades democráticas passavam na época, exigiram uma remodelagem da gestão publica (Martins, 2004). A participação societal e o compartilhamento de algumas decisões com entes da sociedade forneceram as bases para a revisão dos processos de avaliação dos projetos sociais e culturais.

Nesse sentido, a avaliação da gestão pública se faz presente no que tange a adoção de procedimentos e metodologias que expressem a viabilidade e os resultados das ações públicas (Martins, 2004).

Durante anos, a produção de conhecimentos técnicos buscou a melhoria dos padrões de gerenciamento do setor público e avaliação de programas públicos. Em verdade, tal avaliação ensejava avaliar a própria performance do aparelho estatal. Ou seja, a eficiência, eficácia e efetividade tornam-se parâmetros para a avaliação das ações governamentais, ao mesmo tempo em que, criam-se também meios de avaliar diferentes alternativas para se obter resultados equivalentes (Kettl, 1998:87).

Avaliar é preciso. É preciso delimitar com clareza o objeto da avaliação, ou melhor, o que se pretende avaliar. Atualmente, na área social, existem modelos centrados em objetivos. Estes são utilizados como requisito para definições dos padrões comportamentais, seleção e criação de situações de teste que evocam esses padrões e em termos de compreensão para que os resultados sejam utilizados de forma construtiva. A avaliação dos projetos sociais e culturais é uma tarefa complexa que exige a averiguação de aspectos quantitativos e qualitativos. A observância de resultados alcançados e esperados apresenta algumas restrições de julgamento. Portanto, cabe escolher o processo avaliativo que atenderá 
melhor ao que se pretende efetivamente observar (Assumpção e Campos, 2011).

Conforme Bertalanffy (901-1972; in Nogueira, 2007), a teoria geral dos sistemas, em especial dos chamados sistemas abertos, influenciou várias disciplinas, entre elas a teoria das organizações. O autor afirma, ainda, que segundo esse enfoque todos objetos complexos e corpos organizados podem ser considerados sistemas: uma máquina, um organismo, uma floresta etc.

Considerando que os projetos sociais fazem parte de parte de um sistema que é composto pela entidade que elabora e executa o projeto, é necessária uma visão mais abrangente que contemple a sua intervenção social interna ou externa à sociedade. Dentro desta perspectiva, se faz necessário um sistema de informações para acompanhamento e controle gerencial das ações das instituições relativas a aspectos sociais, econômicos e ambientais. Há, portanto, necessidade de identificar quais informações são relevantes para tais instituições demonstrarem a sua importância e contribuições sociais, pois um projeto social não se justifica se o conjunto de ações da instituição não tem um impacto social positivo. (Nogueira, 2007).

A abordagem sistêmica e gerencial das instituições torna possível desenvolver critérios e parametrizações de análise. Por outro lado, é necessário identificar os indicadores essenciais para que se possa desenvolver formas de análise válidas e compatíveis com as metas dos projetos sociais e culturais.
Logo, conforme a visão sistêmica, não se pode limitar a simples análise do projeto, sendo necessária uma visão complementar, por meio da análise institucional da sua responsabilidade social.

Também é necessária a avaliação deste sistema, que deve funcionar como uma retroalimentação do sistema, pois contribui para evolução contínua, para análise do que de fato foi contributivo para o desenvolvimento das políticas sociais e para o desenvolvimento dos projetos sociais.

O estudo destaca que a NBC T 15 (Normas Brasileiras de Contabilidade Técnica) que contempla as Informações de Natureza Social e Ambiental podem ser exigidas para as instituições prestarem contas do impacto e da sua colaboração social e cultural. A NBC T 15 contempla 4 dimensões que são: 1) a geração e a distribuição de riqueza; 2) os recursos humanos; 3) a interação da entidade com o ambiente externo; 4) a interação com o meio ambiente. Tais dimensões podem possibilitar análises complementares que possibilitam a avaliação sistêmica.

Destaca-se que a elaboração do balanço social de forma isolada não cumpre o seu papel sistêmico para análise social e ambiental, devendo ser complementado com: 
- Indicadores específicos dos projetos sociais.

- Elaboração de quocientes, que possibilite relativizar indicadores.

- Análise horizontal de indicadores e quocientes, para visualização do desempenho temporal.

- Aprimoramento contínuo e desenvolvimento de novos indicadores institucionais complementares.

Referências Bibliograficas

ACURCIO, F. A.; CHERCHIGLIA, M. L. \& SANTOS, M. A. Avaliação de qualidade de serviços de saúde. Saúde em Debate, 33:50-53. Escola Nacional de Saúde Pública, Rio de Janeiro: Fundação Oswaldo Cruz, 1991.

AGUILAR, M. J. \& ANDER-EGG, E.Avaliação de Serviços e Programas Sociais. Petrópolis: Editora Vozes, 1994.

ANTHONY, R. N. e GOVINDARAJAN, V. Sistemas de Controle Gerencial. Tradução: NEVES, A. F. São Paulo: Atlas, 2006.

ASSAF NETO, Alexandre. Estrutura e análise de balanços: um enfoque econômico financeiro. 9. ed.. São Paulo: Atlas, 2010.
ASSUMPÇAO, Jairo J e CAMPOS, Lucila M de S. Avaliação de Projetos Sociais em ONGs da Grande Florianópolis: um estudo sobre modelos relacionados ao foco de atuação. Revista de Administração Pública, 45(1):209-42, jan./fev. Rio de Janeiro: Fundação Getúlio Vargas, 2011.

CFC - CONSELHO FEDERAL DE CONTABILIDADE. Norma Brasileira de Contabilidade - CFC NBC T 15, de 19 de agosto de 2004 - Informações de Natureza Social e Ambiental. Brasília: CFC, 2004.

CONTANDRIOPOULOS et alli. A Avaliação na Área de Saúde: Conceitos e Métodos. In: Avaliação em Saúde: Dos Modelos Conceituais à Prática na Análise da Implantação de Programas (Z. M. A. Hartz, org.), pp. 29-47, Rio de Janeiro: Editora Fiocruz, 1997.

COSTA, Frederico L, CASTANHAR , José C. Avaliação de Programas Públicos: Desafios Conceituais e Metodológicos. Revista de Administração Pública. 37(5):969-92, Set./Out. Rio de Janeiro: Fundação Getúlio Vargas, 2003.

GHISONI, S. M. Analisi Di Bilancio. Milano: FAG, 2011.

KETTL, Donald F. (1996) A revolução global: reforma da administração do setor público. In: BRESSER-PEREIRA, Luiz Carlos; SPINK, Peter. Reforma do Estado e administração pública gerencial. Rio de Janeiro: FGV, 1998. 
LAUDON, K. C. e LAUDON, J. P. Gerenciamento de Sistemas de Informação. 3 ed. Rio de Janeiro: LTC, 2001.

MATARAZZO, Dante Carmine. Análise financeira de balanços. 7. Ed. São Paulo: Atlas, 2010.

NOGUEIRA, A. J. F. M. Teoria Geral da Administração para o Século XXI. São Paulo: Ática, 2007.

PIRES, Marcos C. Economia brasileira: da colônia ao Governo Lula. Ed.Saraiva, São Paulo, 2010.

SANTOS, F. A. Ética e Responsabilidade Social: Uma Prática Cotidiana. in BARROS NETO, J. P. de (org.) Administração de Organizações Complexas: liderando e simplificando a gestão para criar valor e maximizar resultados. Rio de Janeiro: Qualitymark, 2009.

TINOCO, J. E. P. Balanço Social e Rentabilidade da Sustentabilidade. São Paulo: Atlas, 2010.

UNIVERSIDADE DO PORTO. Balanço Social 2011. Porto: Universidade do Porto, 2012. Disponível em: http://www.up.pt. Acesso em 8/10/2012. 